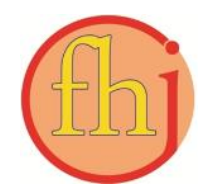

Faletehan Health Journal, 7 (2) (2020) 92-96

www. journal.Ippm-stikesfa.ac.id/ojs/index.php/FHJ

ISSN 2088-673X | e-ISSN 2597-8667

\title{
Efektifitas Penyuluhan Kesehatan terhadap Peningkatan Sikap dan Motivasi dalam Pencegahan Anemia Defisiensi Zat Besi pada Ibu Hamil
}

\author{
Darmawati ${ }^{*}$, Elly Wardani ${ }^{2}$, Cut Husna ${ }^{3}$, Nia Saumiana ${ }^{4}$ \\ 1,2,3,4 Fakultas Keperawatan Universitas Syiah Kuala Banda Aceh \\ *Corresponding Author: darmawati.fkep@unsyiah.ac.id
}

\begin{abstract}
Abstrak
Anemia defisiensi zat besi merupakan jenis anemia yang paling banyak terjadi pada ibu hamil, yaitu sekitar $75 \%$ dari semua jenis anemia. Selain itu, menjadi penyebab utama kematian maternal diantaranya perdarahan postpartum, eklampsi, infeksi, dan plasenta previa. Oleh karena itu diperlukan sikap dan motivasi dari ibu untuk mencegah terjadinya hal tersebut. Salah satu upaya yang dapat dilakukan untuk meningkatkan sikap dan motivasi yaitu dengan penyuluhan kesehatan. Tujuan penelitian ini untuk mengetahui efektifitas dari penyuluhan kesehatan terhadap peningkatan sikap dan motivasi dalam pencegahan anemia defisiensi zat besi pada ibu hamil. Jenis penelitian ini experimental study dengan one group pre-post test design. Pengambilan sampel dilakukan dengan teknik quota sampling dan diperoleh 50 responden. Instrumen penelitian yang digunakan dalam penelitian ini adalah kuesioner sikap dan motivasi yang dianalisa menggunakan wilcoxon sign test. Hasil penelitian menunjukkan bahwa penyuluhan kesehatan efektif untuk meningkatkan sikap ( $p$-value 0,001 ) serta motivasi ( $p$ value 0,001 ) pada responden, dengan selisih mean pre-test dan post-test masing-masing sebanyak 4,46 dan 1,86. Diharapkan kepada petugas kesehatan untuk meningkatkan program penyuluhan kesehatan mengenai anemia defisiensi zat besi, agar ibu hamil memiliki sikap yang positif dan motivasi yang tinggi untuk mencegah anemia defisiensi zat besi.

Kata Kunci: Anemia Defisiensi Besi, Motivasi, Penyuluhan Kesehatan, Sikap
\end{abstract}

\section{The Effectivity of Health Counseling to the Increase of Attitude and Motivation in Preventing Iron Deficiency Anemia in Pregnant Women}

\begin{abstract}
Iron deficiency anemia is the common type of anemia which is about 75\% of all types of anemia and it is known as the death cause of maternal including postpartum hemorrhage, eclampsia, infectious diseases, and placenta previa. Attitude and motivation of the mother are needed to prevent iron deficiency anemia from causing this condition. One of the efforts that could be done is through health counseling. This research aimed to understand the effectiveness of health counseling toward attitude and motivation in preventing iron deficiency anemia among pregnant women. The research was an experimental study with one group pre-test post-test design. Sample collection technique implemented was quota sampling with 50 respondents. Data collection was carried out using questionnaires attitude and motivation that had been analyzed by using Wilcoxon sign test. The result showed that health counseling was effective in increasing respondent's attitude ( $p$-value was 0.000 ) and motivation ( $p$-value was 0,000$)$, with the difference in the mean value of pre-test and post-test were 4.46 and 1.86 respectively. It is expected for health workers to improve counseling programs about iron deficiency anemia, so that pregnant women have a positive attitude and high motivation to prevent iron deficiency anemia.
\end{abstract}

Keywords: Iron Deficiency Anemia, Motivation, Health Counseling, Attitudes 
Faletehan Health Journal, 7 (2) (2020) 92-96

www. journal.Ippm-stikesfa.ac.id/ojs/index.php/FHJ

ISSN 2088-673X | 2597-8667

\section{Pendahuluan}

Angka kematian ibu di Indonesia masih mengalami fluktuasi. Pada tahun 2015 tercatat 305 kematian ibu per 100.000 kelahiran hidup (Kemenkes RI, 2017). Rasio kematian ibu di Aceh pada tahun 2016 adalah 167 per 100.000 kelahiran hidup, yaitu 76 (45\%) kasus kematian ibu nifas, 65 (38\%) kematian ibu bersalin dan 28 (17\%) kasus kematian ibu dalam keadaan hamil (Dinkes Aceh, 2017).

Penyebab utama kematian maternal antara lain perdarahan postpartum, eklampsi, penyakit infeksi, dan plasenta previa yang semua bersumber pada anemia defisiensi besi (Purbadewi \& Ulvie, 2013). Hasil riset daerah tahun 2013 tercatat anemia terjadi pada $37,1 \%$ ibu hamil di Indonesia, $36,4 \%$ ibu hamil di perkotaan dan 37,8\% ibu hamil di perdesaan (Kemenkes RI, 2017). Defisiensi yang timbul akibat adanya perpindahan suplai dan simpanan zat besi dari ibu ke janin secara global menjadi penyebab anemia yang paling umum (Achebe \& Gafter-gvili, 2017).

Terdapat beberapa tinjauan intervensi untuk mengontrol anemia defisiensi zat besi, yaitu, pemberian suplemen besi, intervensi berbasis makanan, kontrol cacing/infeksi, kontrol malaria, serta intervensi reproduksi dan obstetri (Lokeshwar, Mehta, Mehta, Shelke, \& Babar, 2011; Stoltzfus \& Dreyfuss, 1998). Tindakan lainnya yang dapat dilakukan adalah melakukan pemeriksaan dan pengawasan kadar hemoglobin karena terdapat hubungan antara pemeriksaan kadar hemoglobin dengan kejadian anemia (Alam, 2012; Darmawati, Tahlil, Siregar, Kamil, \& Audina, 2018), serta penting juga untuk pemberian tablet tambah darah minimal 90 tablet selama kehamilan (Kemenkes RI, 2017).

Tindakan pencegahan tersebut tentu tidak akan efektif dilaksanakan apabila individu terkait tidak memiliki sikap yang positif dan motivasi yang tinggi terkait anemia. Menurut Peyman \& Abdollahi (2016) merencanakan sebuah pendidikan berdasarkan informasi, motivasi, dan model keterampilan perilaku secara positif mempengaruhi semua aspek yang diperlukan untuk menciptakan perilaku yang sehat, dalam hal ini adalah tindakan pencegahan anemia. Pada penelitian yang meneliti tentang perubahan perilaku ini, didapatkan hasil adanya perbedaan yang signifikan pada nilai motivasi. Sebelum diberikan intervensi, tercatat nilai motivasi sebanyak 45,28\% dan setelah diberikan edukasi kesehatan meningkat menjadi $48,78 \%$. Hal ini menunjukkan efek dari intervensi edukasi kesehatan. Studi lainnya mengenai dampak intervensi edukasi menemukan terdapat perbedaan skor sikap yang signifikan sebelum dan sesudah intervensi pemberian edukasi, dimana nilai sikap dari poin 5,92 menjadi 15,34 (Jalambadani, Borji, \& Delkhosh, 2018).

Berdasarkan data-data penelitian di atas, intervensi edukasi dapat menjadi salah satu cara untuk meningkatkan sikap dan motivasi masyarakat dalam mencegah anemia defisiensi zat besi sehingga angka kejadian anemia defisiensi zat besi dapat berkurang, dimana salah satu metode yang dapat digunakan adalah melalui penyuluhan kesehatan mengenai pencegahan anemia. Penelitian ini dilakukan untuk mengetahui efektifitas dari penyuluhan kesehatan terhadap peningkatan sikap dan motivasi dalam pencegahan anemia defisiensi zat besi pada ibu hamil.

\section{Metode Penelitian}

Penelitian ini menggunakan metode experimental study dengan desain one group pretest post-test dimana pengumpulan data dilaksanakan pada tanggal 2 - 13 Juli 2019 di wilayah kerja Puskesmas Baitussalam, Kabupaten Aceh Besar. Sampel pada penelitian ini adalah 50 responden yang ditentukan dengan teknik quota sampling. Pengumpulan data dilakukan dengan pengisian lembar kuesioner yang sebelumnya telah diuji validitas dan reliabilitasnya. Nilai cronbach alpha yang didapatkan pada uji kuesioner ini adalah 0,912 sehingga kuesioner ini reliable untuk digunakan sebagai alat pengumpul data pada penelitian ini. Adapun kuesioner penelitian ini terdiri dari 3 bagian yaitu: 1) bagian pertama berisi data karakteristik responden, 2) bagian kedua berisi pertanyaan untuk menilai sikap dalam pencegahan anemia defisiensi zat besi, dan 3) bagian ketiga berisi pertanyaan untuk menilai motivasi dalam pencegahan anemia defisiensi zat besi. Proses pengumpulan data dilakukan setelah mendapatkan surat lulus uji etik dari Komite Etik Penelitian Fakultas Keperawatan Universitas Syiah Kuala dengan nomor kode etik 111250419047. Penelitian ini dilakukan melalui 3 tahap yaitu pre-test, pelaksanaan intervensi yang dilaksanakan sebanyak 1 kali dengan durasi 1 kali penyuluhan selama 60-75 menit, dan post-test. Intervensi 
konseling dilaksanakan dengan metode penyuluhan dan menggunakan media power point. Pengolahan data dilakukan dengan menggunakan software komputer untuk menjelaskan atau mendeskripsikan karakteristik setiap variabel serta analisa data menggunakan wilcoxon sign test untuk menganalisa efektifitas dari penyuluhan kesehatan yang merupakan variabel independen terhadap variabel dependen dalam penelitian ini.

\section{Hasil dan Pembahasan}

Berdasarkan tabel 1, ditemukan mayoritas responden berusia 20-35 tahun, yaitu sebanyak 36 responden $(72 \%)$. Sebagian besar responden tidak pernah mengikuti penyuluhan anemia sebelumnya, yaitu sebanyak 39 ibu hamil (78\%), serta seluruh responden merupakan Ibu Rumah Tangga (IRT) $(100 \%)$.

Tabel 1. Distribusi frekuensi karakteristik responden

\begin{tabular}{lcc}
\hline \multicolumn{1}{c}{ Karakteristik } & f & \% \\
\hline Usia & 1 & 2 \\
$\quad<20$ tahun & 36 & 72 \\
$\quad 20-35$ tahun & 13 & 26 \\
$\quad>35$ tahun & & \\
\hline Penyuluhan & & \\
Kesehatan Anemia & & \\
Sebelumnya & & 22 \\
$\quad$ Pernah & 11 & 78 \\
$\quad$ Tidak Pernah & 39 & \\
\hline Pekerjaan & & 100 \\
$\quad$ Ibu Rumah Tangga & 50 & 100 \\
\hline Jumlah & 50 &
\end{tabular}

Berdasarkan hasil pengumpulan dan pengolahan data pada tabel 2, dapat disimpulkan bahwa mayoritas ibu hamil memiliki sikap positif terhadap pencegahan anemia defisiensi zat besi sebelum dan sesudah intervensi yaitu masingmasing sebanyak 27 responden (54\%) dan 28 responden $(56 \%)$.

Pada variabel motivasi dapat diketahui bahwa mayoritas ibu hamil memiliki motivasi rendah dalam pencegahan anemia defisiensi zat besi sebelum intervensi, yaitu sebanyak 26 responden $(52.0 \%)$. Sesudah pemberian penyuluhan kesehatan, sebagian besar ibu hamil memiliki motivasi tinggi, yaitu sebanyak 38 responden $(76.0 \%)$.
Pada tabel 3 menunjukkan bahwa pada variabel sikap ditemukan terdapat perbedaan nilai rata-rata sikap ibu hamil dalam pencegahan anemia sebelum dan sesudah diberikan intervensi penyuluhan kesehatan dengan nilai masing-masing yaitu pre-test 29,52 dan post-test 33,98. Terlihat bahwa selisih nilai mean sebelum dan sesudah intervensi adalah sebesar 4,46. Berdasarkan analisa, didapatkan nilai kemaknaan $(\mathrm{p}=0,000$; $\alpha=0,05$ ), ini berarti $\mathrm{H}_{0}$ ditolak, dengan kata lain dapat disimpulkan bahwa terdapat perbedaan signifikan antara nilai rata-rata sikap pre-test dan post-test yang artinya pemberian penyuluhan kesehatan efektif untuk meningkatkan sikap dalam pencegahan anemia defisiensi zat besi pada ibu hamil.

Jika merujuk pada konsep, istilah sikap didefinisikan sebagai tanggapan atau pendapat mengenai sesuatu hal yang belum dilakukan atau menimbulkan suatu tindakan, yang bisa terwujud dalam bentuk pendapat senang atau tidak senang maupun setuju atau tidak setuju. Pada hasil penelitian ini, jelas terlihat bahwa sikap seorang individu dapat berubah ketika mereka terpapar informasi yang mereka yakini kebenarannya, dimana sebelum intervensi penyuluhan kesehatan berlangsung, hanya terdapat 27 responden $(54,0 \%)$ yang memiliki sikap positif dan setelah intervensi menjadi 28 responden $(56,0 \%)$. Kenaikan sikap positif sebelum dan setelah diberikan intervensi pada penelitian ini tidak tampak signifikan. Hal ini dapat dipengaruhi oleh kondisi kesehatan ibu hamil yang mempengaruhi kemampuan ibu hamil untuk hadir dan berkonsentrasi penuh untuk mengikuti kegiatan penyuluhan yang dilakukan. Hal ini juga dapat dihubungkan dengan jenis pekerjaan dimana keseluruhan responden merupakan ibu rumah tangga yang berfungsi ganda selain mengurus diri, juga harus mengurus keluarganya.

Pada penelitian lainnya yang telah dilakukan oleh Jalambo, Sharif, Naser, dan Karim (2017) terdapat peningkatan nilai sikap sebelum dan sesudah dilakukan intervensi, yaitu dari 36,4\% menjadi 75,5\%. Selain itu, Sumiyati, Hastuti, dan Widiastuti, (2018) menemukan bahwa 66,7\% dari responden memiliki sikap yang baik sebelum intervensi dan setelah intervensi meningkat menjadi 93,3\%. Penelitian lain yang selaras juga yaitu penelitian yang dilakukan oleh Sholihah dan Hanafi (2017) yang mana pada penelitian tersebut didapatkan terdapat perbedaan nilai rata-rata sikap responden yang awalnya 45,00 menjadi 75,25. 
Faletehan Health Journal, 7 (2) (2020) 92-96

www. journal.Ippm-stikesfa.ac.id/ojs/index.php/FHJ

ISSN 2088-673X | 2597-8667

Tabel 2. Distribusi frekuensi variabel penelitian

\begin{tabular}{ccccccc}
\hline \multirow{2}{*}{ No } & \multirow{2}{*}{ Variabel } & \multirow{2}{*}{ Kategori } & \multicolumn{2}{c}{ Pre-test } & \multicolumn{2}{c}{ Post-test } \\
\cline { 3 - 6 } & & f & $\%$ & $\mathrm{f}$ & $\%$ \\
\hline \multirow{2}{*}{1.} & \multirow{2}{*}{ Sikap } & Positif & 27 & 54 & 28 & 56 \\
\multirow{2}{*}{2.} & Negatif & 23 & 46 & 22 & 44 \\
& \multirow{2}{*}{ Motivasi } & Tinggi & 24 & 48 & 38 & 76 \\
& & Rendah & 26 & 52 & 12 & 24 \\
\hline
\end{tabular}

Tabel 3. Perbedaan nilai sikap dan motivasi ibu hamil dalam pencegahan anemia defisiensi zat besi

\begin{tabular}{lcccccc}
\hline No & Variabel & Hasil & Mean & Std. Deviation & $\mathrm{Z}$ & p-value \\
\hline \multirow{2}{*}{ 1. } & \multirow{2}{*}{ Sikap } & Pre-test & 29,52 & 5,607 & $-6,116$ & 0,000 \\
& & Post-test & 33,98 & 4,058 & & \\
& & & & & \\
2. & Motivasi & Pre-test & 9,18 & 2,135 & $-5,492$ & 0,000 \\
& & Post-test & 11,04 & 1,124 & & \\
\hline
\end{tabular}

Selain aspek sikap pada ibu hamil, pada hasil penelitian ini juga terlihat adanya perbedaan nilai rata-rata motivasi ibu hamil dalam pencegahan anemia sebelum dan sesudah diberikan intervensi penyuluhan kesehatan dengan nilai masing-masing yaitu pre-test 9,18 dan post-test 11,04 . Terlihat bahwa selisih nilai mean sebelum dan sesudah intervensi adalah sebesar 1,86. Berdasarkan analisa data, didapatkan nilai kemaknaan $(p=0,000$; $\alpha=0,05)$, ini berarti $\mathrm{H}_{0}$ ditolak sehingga dapat disimpulkan bahwa terdapat perbedaan signifikan antara nilai rata-rata sikap pre-test dan post-test, yang bermakna bahwa pemberian penyuluhan kesehatan efektif untuk meningkatkan motivasi dalam pencegahan anemia defisiensi zat besi pada ibu hamil.

Terjadinya peningkatan motivasi pada penelitian ini dikarenakan materi tentang anemia defisiensi besi yang diberikan kepada ibu hamil. Pada intervensi penyuluhan, ibu hamil dibekali informasi tentang definisi, penyebab, tanda gejala, akibat, dan cara pencegahan anemia defisiensi zat besi pada ibu hamil. Keseluruhan pemberian informasi ini mengakibatkan penambahan informasi baru bagi ibu sehingga saat ibu hamil mengetahui apa dampak anemia defisiensi zat besi pada dirinya dan janinnya, maka ibu termotivasi untuk mencegah hal itu terjadi sehingga timbul dorongan berupa kemauan dan kesadaran ibu untuk mencegah anemia defisiensi besi. Hal ini dikarenakan individu cenderung termotivasi terhadap suatu hal yang memiliki dampak yang baik atau bermanfaat bagi dirinya. Sebelum intervensi berlangsung, terdapat sebanyak $52 \%$ responden yang memiliki motivasi yang rendah dan belum memiliki kesadaran untuk melakukan pencegahan terkait anemia defisiensi zat besi. Hal ini dapat diakibatkan karena ibu hamil belum pernah terpapar informasi tentang anemia defisiensi zat besi, atau mereka hanya sekedar tahu tetapi belum ada kesadaran dari diri sendiri untuk mencegahnya. Hal ini dapat dilihat dari data bahwa hanya $22 \%$ yang pernah mendapatkan penyuluhan tentang anemia sedangkan sisanya.

Hasil penelitian ini juga sejalan dengan penelitian yang dilakukan oleh Ningsih (2011) dimana pada penelitian tersebut nilai rata-rata pretest terkait motivasi adalah 39,1765 dan saat posttest meningkat menjadi 51,5588. Hasil penelitian ini juga sesuai dengan hasil dari penelitian sebelumnya yang dilakukan oleh Peyman \& Abdollahi (2016) dengan hasil peningkatan signifikan nilai motivasi sebelum intervensi yaitu $45,28 \%$ menjadi $48,78 \%$ setelah diberikan intervensi.

\section{Simpulan}

Berdasarkan hasil penelitian, kesimpulan yang didapatkan adalah penyuluhan kesehatan efektif untuk meningkatkan sikap dan motivasi dalam pencegahan anemia defisiensi zat besi pada ibu hamil. Peningkatan program penyuluhan 
kesehatan perlu dilakukan oleh instansi terkait tentang mengenai anemia defisiensi zat besi, sehingga terbentuk sikap yang positif dan motivasi yang tinggi dalam pencegahan anemia defisiensi zat besi.

\section{Referensi}

Achebe, M. M., \& Gafter-gvili, A. (2017). How I treat anemia in pregnancy: iron, cobalamin, and folate. Blood, 129(8), 940-949. http://doi.org/10.1182/blood-2016-08-672246

Alam, D. K. (2012). Warning! Ibu Hamil. Surakarta: Ziyad Visi Media.

Darmawati, Tahlil, T., Siregar, T. N., Kamil, H., \& Audina, M. (2018). Antenatal care and iron deficiency anemia among pregnant women. In Proceeding of The 8th AIC: Health and Life Sciences 2018 - Syiah Kuala University (pp. 13-24).

Dinkes Aceh. (2017). Profil Kesehatan Aceh Tahun 2016, 1-160.

Jalambadani, Z., Borji, A., \& Delkhosh, M. (2018). The effect of education based on the theory of planned behavior on iron supplementation among pregnant women. Korean Journal of Family Medicine, 39(6), 370-374. http://doi.org/10.4082/kjfm.17.0141

Jalambo, M. O., Naser, I. A., Sharif, R., \& Karim, N. (2017). Knowledge, Attitude and Practices of Iron Deficient and Iron Deficient Anaemic Adolescents in the Gaza Strip , Palestine. Asian Journal of Clinical Nutrition, 9(1), 5156. http://doi.org/10.3923/ajcn.2017.51.56

Kemenkes RI. (2017). Profil Kesehatan Indonesia Tahun 2016. Jakarta: Kementerian Kesehatan Republik Indonesia.

Lokeshwar, M. R., Mehta, M., Mehta, N., Shelke, P., \& Babar, N. (2011). Prevention of Iron
Deficiency Anemia (IDA): How far have we reached? Indian Journal of Pediatrics, 78(5), 593-602. http://doi.org/10.1007/s12098-0100130-1

Ningsih, D. U. (2011). Pengaruh Penyuluhan Kesehatan Terhadap Motivasi dalam Upaya Pencegahan Primer Kanker Serviks Pada Siswi Kelas X di SMA Negeri 1 Sanden, Bantul, Yogyakarta. Sekolah Tinggi Ilmu Kesehatan 'Aisyiyah.

Peyman, N., \& Abdollahi, M. (2016). The relationship between health literacy and selfefficacy physical activity in postpartum women. Journal of Health Literacy, 1(1), 512.

http://doi.org/10.1016/j.annepidem.2008.08.0 91

Purbadewi, L., \& Ulvie, Y. N. S. (2013). Hubungan Tingkat Pengetahuan Tentang Anemia dengan Kejadian Anemia Pada Ibu Hamil, 2(1), 3139.

Sholihah, Q., \& Hanafi, A. S. (2017). The Differences Knowledge, Attitude and Behavior Prior and After Counseling of Anemia and Balance Menus. Journal of Applied Environmental and Biological Sciences, 7(1), 120-127.

Stoltzfus, R. j., \& Dreyfuss, M. 1. (1998). International Nutritional Anemia Consultative Group, WHO, UNICEF Guidelines for the Use of Iron Supplements to Prevent and Treat Iron Deficiency Anemia. Washington DC, USA.

Sumiyati, Hastuti, P., \& Widiastuti, A. (2018). Efektivitas penyuluhan kesehatan terhadap pengetahuan dan sikap ibu balita tentang TB partu pada anak di Kabupaten Banyumas. Link, 14(1), 7-13. 